\title{
Freeze-Thaw Cycle Effect on Sputtering Rate of Water-Saturated Yellow Sandstone under Impact Loading
}

\author{
Yunbing Hu $\mathbb{D}^{1},{ }^{1}$ Tianzhu Duan $\mathbb{D},{ }^{1}$ Penghui Xian $\mathbb{D},{ }^{1}$ and Liang Chen $\mathbb{D}^{2}$ \\ ${ }^{1}$ China Coal Technology and Engineering Group Chongqing Research Institute, Chongqing 400039, China \\ ${ }^{2}$ State Key Laboratory for Geomechanics and Deep Underground Engineering of China University of Mining and Technology, \\ Xuzhou, Jiangsu Province 221008, China \\ Correspondence should be addressed to Tianzhu Duan; duantianzhu@163.com
}

Received 22 June 2019; Revised 15 September 2019; Accepted 23 September 2019; Published 6 November 2019

Guest Editor: Tae-Hyung Kim

Copyright (c) 2019 Yunbing Hu et al. This is an open access article distributed under the Creative Commons Attribution License, which permits unrestricted use, distribution, and reproduction in any medium, provided the original work is properly cited.

In order to explore the impact of freeze-thaw temperature on the sputtering rate of water-saturated yellow sandstone under impact loading, in this paper, the Hopkinson pressure bar is used to conduct impact loading test on the water-saturated yellow sandstone at the same strain rate $\left(74.22 \mathrm{~s}^{-1}\right)$ under five different freeze-thaw temperatures. After impact loading, the yellow sandstone fragments are graded and screened by using the sizing screen, and the mass of fragments with different particle sizes after screening is counted. By transforming the fragments into spheres with the corresponding particle sizes, and combining the dissipated energy, the surface specific energy of yellow sandstone with different freeze-thaw temperatures is calculated. Finally, the sputtering rate of the fragments is obtained by using the relationship of total work, dissipated energy, and kinetic energy. The main conclusions are as follows: The freeze-thaw temperature has a significant effect on the fracture degree of yellow sandstone. The lower the freeze-thaw temperature is, the higher the fracture degree of yellow sandstone is, and the smaller the particle size distribution of fragments is. The fractal dimension of yellow sandstone increases with the decrease of freeze-thaw temperature, indicating that the damage of yellow sandstone is more serious. The dissipative energy of yellow sandstone increases with the decrease of freezing temperature, while the kinetic energy increases gradually when the freeze-thaw temperature is $-30^{\circ} \mathrm{C}$ to $-15^{\circ} \mathrm{C}$ and decreases gradually when the freeze-thaw temperature is $-15^{\circ} \mathrm{C}$ to $-5^{\circ} \mathrm{C}$. The surface area and surface specific energy of yellow sandstone fragments both increase with the increase of freeze-thaw temperature. And the sputtering rate of yellow sandstone fragments increases gradually at freezing temperature from $-30^{\circ} \mathrm{C}$ to $-15^{\circ} \mathrm{C}$ and decreases gradually at $-15^{\circ} \mathrm{C}$ to $-5^{\circ} \mathrm{C}$. Therefore, from the perspective of dynamic destruction process, the sputtering of yellow sandstone fragments at freezing temperatures of $-15^{\circ} \mathrm{C},-20^{\circ} \mathrm{C}$, and $-30^{\circ} \mathrm{C}$ is more intense than that at $-5^{\circ} \mathrm{C}$ and $-10^{\circ} \mathrm{C}$. The results can provide some guidance for production in winter and winter regions.

\section{Introduction}

In the frost area, the seasons change obviously, and the rainfall or groundwater is abundant, so the temperature difference between day and night in this area is too large, which will easily lead to the phenomenon of freezing and thawing of water-saturated rocks $[1,2]$. The process of freezing and thawing affects the stability of water-saturated rocks [3]. However, in the process of coal open-pit mining and tunnel tunneling, in addition to freezing-thawing phenomenon, it is often accompanied by the impact load on rocks. Under the impact load, the energy inside the rocks accumulates and releases rapidly for a short time [4, 5], resulting in rock fragments sputtering around. Therefore, it is of great significance to take freeze-thaw temperature as a prominent factor to study the impact load and freeze-thaw cycle on the sputtering rate of water-saturated yellow sandstone.

As a brittle material with disordered internal pores, rock has a significant impact on rock crack evolution under freeze-thaw conditions [6-10]. When the water-saturated rock is under freeze-thaw conditions, the water connects microcracks and generates expansion [11] in the rock, which aggravates the development of these cracks. The 
development of these cracks is mainly manifested in the following aspects: on the one hand, the size of these cracks is further increased [12]; on the other hand, the crack tip continues to extend; meanwhile, in the local cracks, adjacent cracks close due to expansion of ice, while the size of cracks without water filling shrinks [13]. In addition, freezing and thawing will also have an impact on the water polymer. When the temperature drops, some water polymer particles inside the rock shrink, leading to local collapse, which affects the overall internal structure of the rock to a certain extent [14]. Due to the change of pore structure inside the rock, the physical and mechanical parameters of the rock change, such as compressive strength [15-17], tensile strength [18], damage [19], acoustic emission [20-22], pore structure [23], and resistivity [24, 25]. Ince et al. [26] collected 10 volcanic clastic rock samples from Cappadocia for test. Water-saturated rock was frozen in 12 hours at $-18 \pm 2.5^{\circ} \mathrm{C}$ and then thawed for 12 hours at $32 \pm 2.5^{\circ} \mathrm{C}$, so after 30 times, the compressive strength, $\mathrm{P}$ wave velocity, dry density, point load strength index, and coefficient of durability test of samples after the freeze-thaw cycle were measured. So the multiple linear regression equations of the above parameters are obtained, and the equations can well predict the impact of the freeze-thaw cycle on rock compressive strength in other areas. Zhou et al. [27] conducted large-scale triaxial tests on roadbed gravel soil samples after the freeze-thaw cycle. And it is found that the elastic modulus and shear strength of soil-rock mixture decreased after the freeze-thaw cycle.

Moreover, with the introduction of some advanced equipment, such as Hopkinson pressure bar test system, the high-speed camera, and other advanced equipment, a large number of scholars used Hopkinson pressure bar test system to carry out the impact load test on rocks treated by freezethaw cycle. It is found that freeze-thaw cycle has an important influence on physical and mechanical parameters and energy dissipation of water-saturated rocks under high strain rate [28-33]. This influence is mainly reflected in the different internal structures of water-saturated rocks treated with different freeze-thaw cycle temperatures under high strain rate, leading to differences in energy transformation within the rocks. Wang et al. [34-36] studied the effects of impact loading and freeze-thaw cycle (freeze-thaw temperature ranges from $-20^{\circ} \mathrm{C}$ to $20^{\circ} \mathrm{C}$, with cycles of $0,5,10$, 15 , and 25 times, respectively) on the damage of red sandstone. It is found that the peak strength and elastic modulus of red sandstone after freeze-thaw decrease with the increase of cycle times when the strain rates are different. But the damage, which is defined by total power and dissipated energy, increases with the increase of cycle times. Ke et al. $[37,38]$ conducted NMR tests on rocks after freezethaw cycle (freeze-thaw temperature ranges from $-20^{\circ} \mathrm{C}$ to $20^{\circ} \mathrm{C}$, with cycles of $0,20,60,100$, and 140 times, respectively) and did dynamic experiments on rocks under strain rate $\left(75 \mathrm{~s}^{-1}\right)$ using the SHPB system. It is found that, with the increase of freeze-thaw cycle, the porosity of sandstone increases, the evolution of pore size tends to be uniform, the dynamic peak stress decreases, and the energy absorption increases. Therefore, this series of research results shows that freeze-thaw has an important influence on the evolution law of physical and mechanical parameters of water-saturated rocks, and the change of physical and mechanical parameters will eventually affect the absorption and transformation of internal energy of rocks under external loads.

At present, some scholars mainly focus on the impact of freeze-thaw on physical and mechanical properties and energy dissipation of rocks by changing the internal structure of rocks and rarely study the change law of rock fragments sputtering rate under the impact load [39], especially taking the freeze-thaw cycle into a prominent factor. Therefore, in this paper, the freeze-thaw cycles of the watersaturated yellow sandstone were performed for 8 times at $-5^{\circ} \mathrm{C},-10^{\circ} \mathrm{C},-15^{\circ} \mathrm{C},-20^{\circ} \mathrm{C}$, and $-30^{\circ} \mathrm{C}$, respectively. Then, impact tests were carried out on the yellow sandstone samples after freeze-thaw cycles. The impact of freeze-thaw cycles on the sputtering rate of fragments was studied by using the relationship between fragments and energy. And the results can be used to guide the sputtering rate of rock burst in seasonal frost zone.

\section{Test Equipment and Methods}

\subsection{Preparation of Freeze-Thaw Samples}

2.1.1. The Production Process of Original Sample. In this paper, the sample was selected from a mine in Inner Mongolia. After drilling, cutting, and polishing, the original sample was finally made into a cylinder of $25 \times 50 \mathrm{~mm}$ (height $\times$ diameter). According to the test requirements, the nonparallelism at both ends of the cylinder is less than $0.5 \%$, and the flatness of the end face is ensured. The final samples are shown in Figure 1.

\subsubsection{Water Saturation of Yellow Sandstone Samples.} The prepared original sample was placed in the electric thermostatic drying box DHG9076 and dried at $105^{\circ} \mathrm{C}$ for 24 hours. The quality of yellow sandstone samples before and after drying was recorded for several times until the quality difference was less than $0.01 \mathrm{~g}$, which means that the yellow sandstone has been dried off at this time.

Then, the dried samples were placed in a sealed tank and pumped with water and air for 24 hours at a vacuum pressure of $-0.09 \mathrm{MPa}$, until there was no bubble overflow on the surface of the samples, and then, the pressure of the sealed tank was adjusted to the standard atmosphere. When the mass change of the sample is less than $0.01 \mathrm{~g}$, it is considered that the sample has been saturated at this time. The saturation rate of the sample obtained by forced saturation treatment with vacuum extraction method is $5.71 \%$. All the saturated patterns were divided into five groups, three in each group.

\subsubsection{Freeze-Thaw Process of Yellow Sandstone Samples.} The samples after water saturation were placed in the freezer and thermostat for freeze-thaw cycle treatment $[40,41]$. In the freezer, the water-saturated samples experienced two 


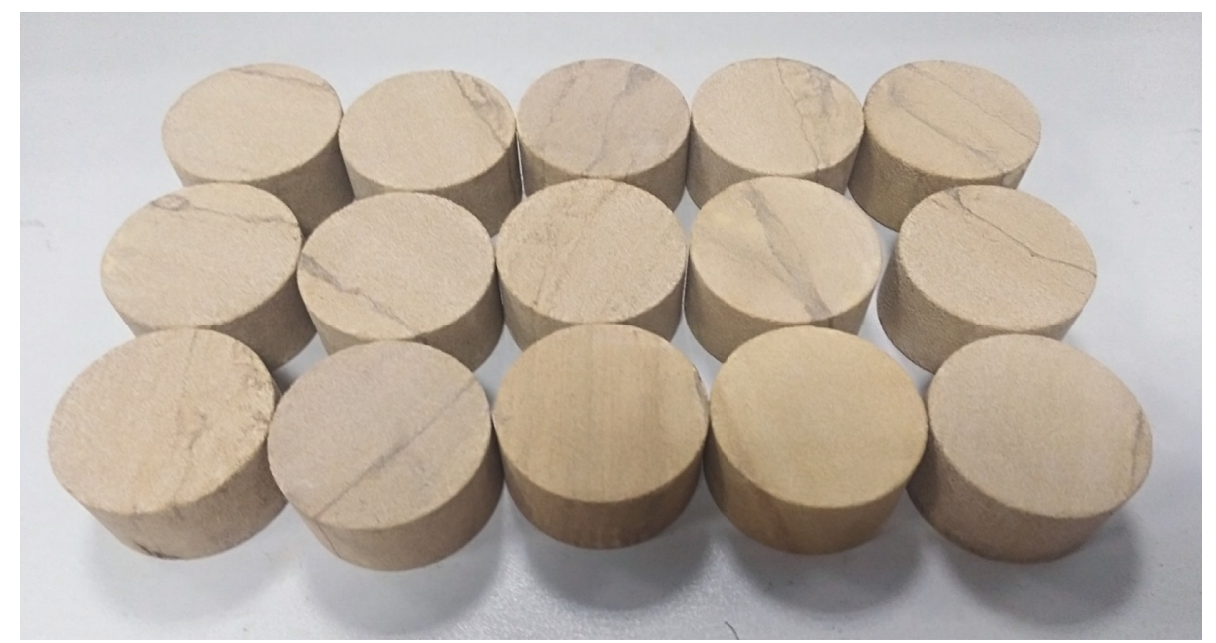

FIGURE 1: Yellow sandstone samples.

hours of temperature changing, falling from $25^{\circ} \mathrm{C}$ to $-5^{\circ} \mathrm{C}$, $-10^{\circ} \mathrm{C},-15^{\circ} \mathrm{C},-20^{\circ} \mathrm{C}$, and $-30^{\circ} \mathrm{C}$, respectively. When the sample reaches the set temperature, it is kept in a freezer for six hours and then placed in a thermostat of $25^{\circ} \mathrm{C}$ for two hours. This process is repeated for 7 times, and the total number of freeze-thaw cycles is 8 times. The temperature change process is shown in Figure 2.

The standard model of saturated yellow sandstone after freeze-thaw cycle was subjected to uniaxial compression test. The physical parameters of saturated yellow sandstone after freeze-thaw cycle were obtained as shown in Table 1.

2.2. Test Equipment and Methods. This impact load test equipment is carried out by Hopkinson pressure bar system, as shown in Figure 3. The experimental system includes dynamic loading system, pressure bar system, energy absorption system, and signal acquisition and processing system. During the test, the bullet strikes the incident bar, and the velocity of the impact bar is measured by the speedometer. The incident and reflected wave signals are collected by the strain gauge on the incident bar, and the transmitted wave signals are collected by the strain gauge on the transmission bar.

Figure 4 shows the SHPB impact test system. In order to observe the dynamic damage process of yellow sandstone, high-speed camera was used.

Test process: firstly, a certain amount of Vaseline is daubed on both ends of the sample, and it is fixed in the middle of the incidence bar and transmission bar. Next, the control valve and high-speed camera are opened, and when the set pressure is reached in the launching chamber, the bullet is driven by gas to hit the incident bar to complete the impact test. During the test, the velocity of the impact bar was obtained by the speedometer, the data of incident wave, reflected wave, and transmitted wave were collected by the strain gauge on the incident bar and transmission bar, and the whole process of sample destruction was captured by the high-speed camera. The typical incident, reflected, and transmitted waves obtained in this experiment are shown in Figure 5.

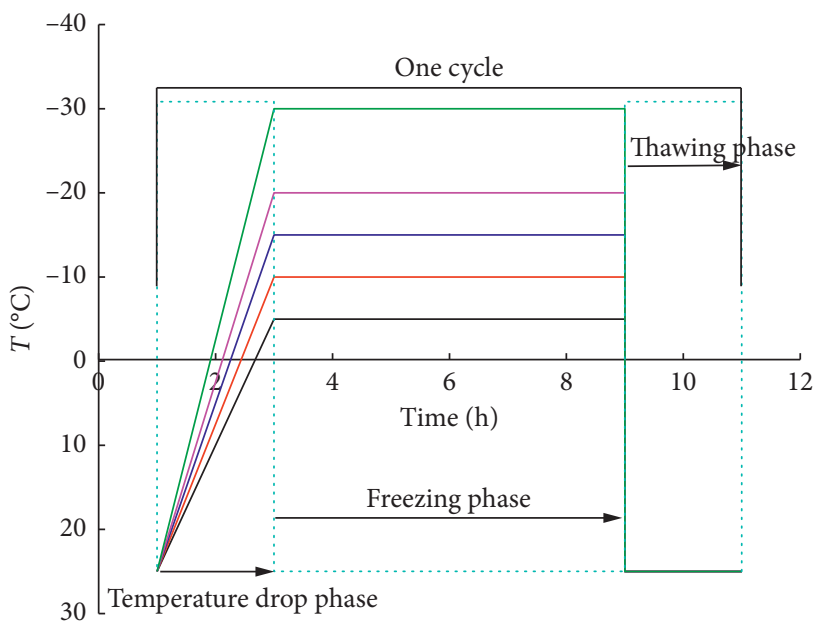

Figure 2: Temperature-time curve of freeze-thaw cycle.

\section{Effect of Freeze-Thaw Temperature on Macroscopic Properties of Yellow Sandstone}

3.1. Effect of Freeze-Thaw Temperature on Stress-Strain Curve of Yellow Sandstone. Figure 6 shows the stress-strain curve of yellow sandstone at different temperatures. It can be seen that the stress-strain curve of yellow sandstone at different temperatures has a certain temperature effect, which is mainly reflected in the following:

(1) The mechanical properties of yellow sandstone have obvious temperature effect with the change of temperature. For the stress-strain curve, the slope of linear elastic rising stage and the postpeak descending stage decreases gradually.

(2) Different freezing-thawing temperatures have significant effects on peak strength, peak strain, and dynamic elastic modulus of water-saturated yellow sandstone.

From the above stress-strain curve, it can be seen that the mechanical properties are significantly affected by 
TABle 1: Physicomechanical parameters of sandstone under different freeze-thaw temperatures.

\begin{tabular}{|c|c|c|c|c|c|c|c|}
\hline \multirow[b]{2}{*}{ Freezing and thawing temperature $T\left({ }^{\circ} \mathrm{C}\right)$} & \multirow[b]{2}{*}{ Number } & \multicolumn{2}{|c|}{$\sigma_{\mathrm{s}}(\mathrm{MPa})$} & \multicolumn{2}{|c|}{$\varepsilon_{\mathrm{s}}\left(10^{-3}\right)$} & \multicolumn{2}{|c|}{$E_{\mathrm{s}}(\mathrm{GPa})$} \\
\hline & & $\begin{array}{c}\text { Single } \\
\text { sample }\end{array}$ & $\begin{array}{l}\text { Average } \\
\text { value }\end{array}$ & $\begin{array}{c}\text { Single } \\
\text { sample }\end{array}$ & $\begin{array}{l}\text { Average } \\
\text { value }\end{array}$ & $\begin{array}{c}\text { Single } \\
\text { sample }\end{array}$ & $\begin{array}{c}\text { Average } \\
\text { value }\end{array}$ \\
\hline \multirow{3}{*}{25} & T0-1 & 34.56 & \multirow{3}{*}{34.82} & 13.25 & \multirow{3}{*}{13.62} & 4.61 & \multirow{3}{*}{4.43} \\
\hline & T0-2 & 34.18 & & 13.52 & & 4.41 & \\
\hline & T0-3 & 35.72 & & 14.09 & & 4.27 & \\
\hline \multirow{3}{*}{-5} & T1-1 & 30.78 & \multirow{3}{*}{30.57} & 13.68 & \multirow{3}{*}{14.29} & 4.15 & \multirow{3}{*}{4.28} \\
\hline & T1-2 & 29.39 & & 14.47 & & 4.23 & \\
\hline & $\mathrm{T} 1-3$ & 31.54 & & 14.73 & & 4.47 & \\
\hline \multirow{3}{*}{-10} & $\mathrm{~T} 2-1$ & 29.38 & \multirow{3}{*}{30.29} & 15.34 & \multirow{3}{*}{15.26} & 3.81 & \multirow{3}{*}{3.99} \\
\hline & $\mathrm{T} 2-2$ & 30.82 & & 15.12 & & 4.04 & \\
\hline & $\mathrm{T} 2-3$ & 30.67 & & 15.31 & & 4.12 & \\
\hline \multirow{3}{*}{-15} & T3-1 & 27.54 & \multirow{3}{*}{28.57} & 15.52 & \multirow{3}{*}{15.51} & 3.44 & \multirow{3}{*}{3.35} \\
\hline & T3-2 & 29.19 & & 15.87 & & 3.15 & \\
\hline & T3-3 & 28.98 & & 15.13 & & 3.45 & \\
\hline \multirow{3}{*}{-20} & T4-1 & 25.41 & \multirow{3}{*}{26.43} & 17.54 & \multirow{3}{*}{17.34} & 3.35 & \multirow{3}{*}{3.06} \\
\hline & T4-2 & 26.09 & & 17.07 & & 2.95 & \\
\hline & T4-3 & 27.79 & & 17.41 & & 2.87 & \\
\hline \multirow{3}{*}{-30} & T5-1 & 25.41 & \multirow{3}{*}{24.39} & 18.86 & \multirow{3}{*}{18.71} & 2.72 & \multirow{3}{*}{2.80} \\
\hline & T5-2 & 23.66 & & 19.00 & & 2.58 & \\
\hline & T5-3 & 24.09 & & 18.26 & & 3.10 & \\
\hline
\end{tabular}

Note: $\sigma_{\mathrm{s}}$ is the uniaxial compressive strength, $\varepsilon_{\mathrm{s}}$ is the peak strain, and $E_{\mathrm{s}}$ is the elastic modulus.

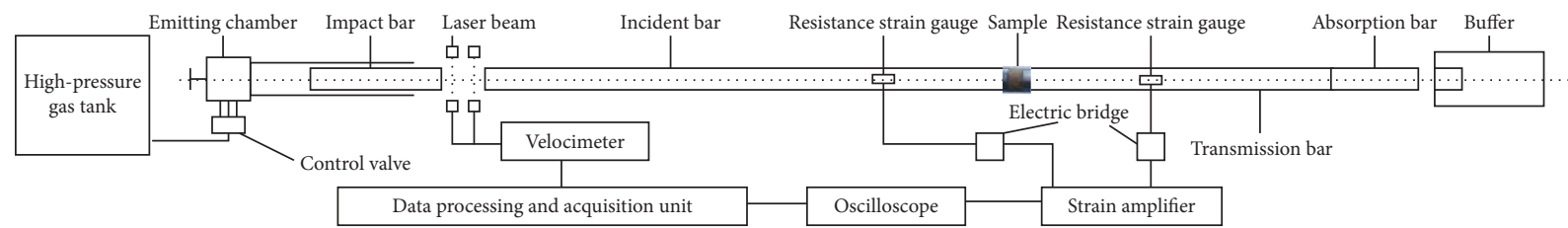

FIgURE 3: Hopkinson pressure bar system.

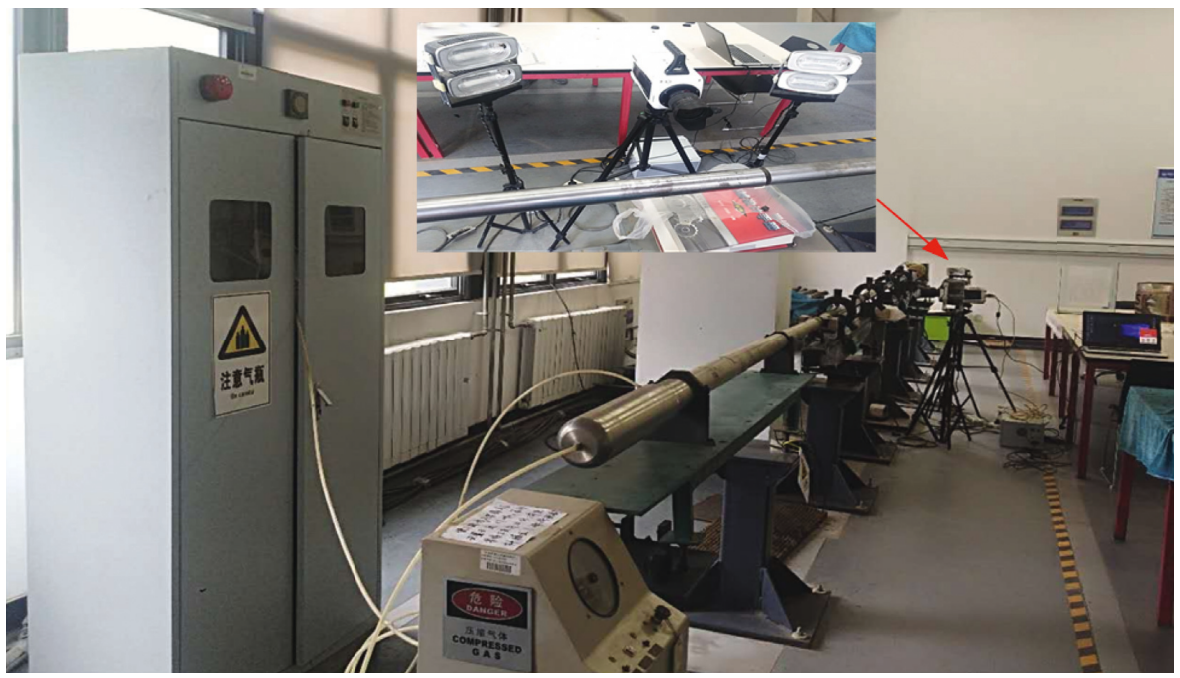

FIgURE 4: Hopkinson impact apparatus.

temperature. This is because the lower the freeze-thaw temperature is, the more obvious the development and expansion of internal cracks in the sample will be, which will lead to the reduction of the internal integrity of the sample. Finally, the physical properties of the sample will change under the impact load.
3.2. Particle Size Distribution of Yellow Sandstone Fragments at Freeze-Thaw Temperature. Particle size distribution is the macroscopic manifestation of rock damage [40]. The analysis of particle size distribution can directly reflect the impact of freeze-thaw temperature on the damage degree of sandstone. In order to describe the particle size distribution 


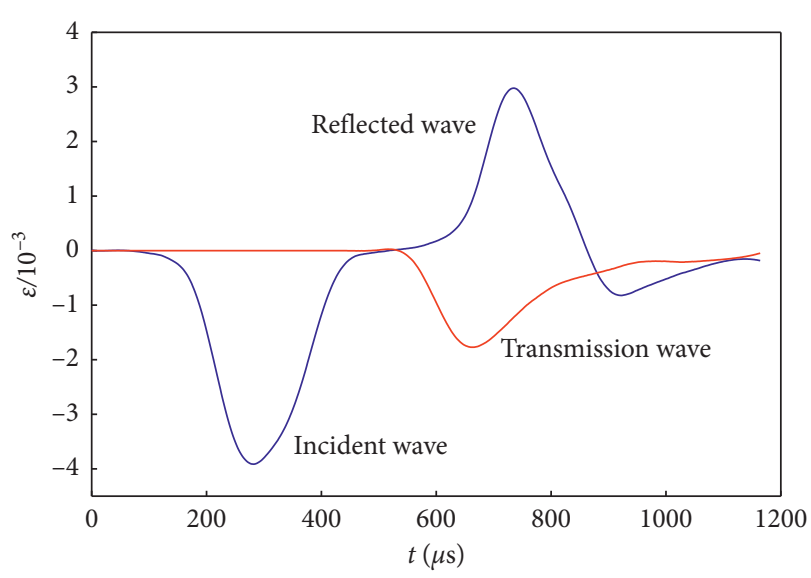

Figure 5: The shock signal of SHPB test.

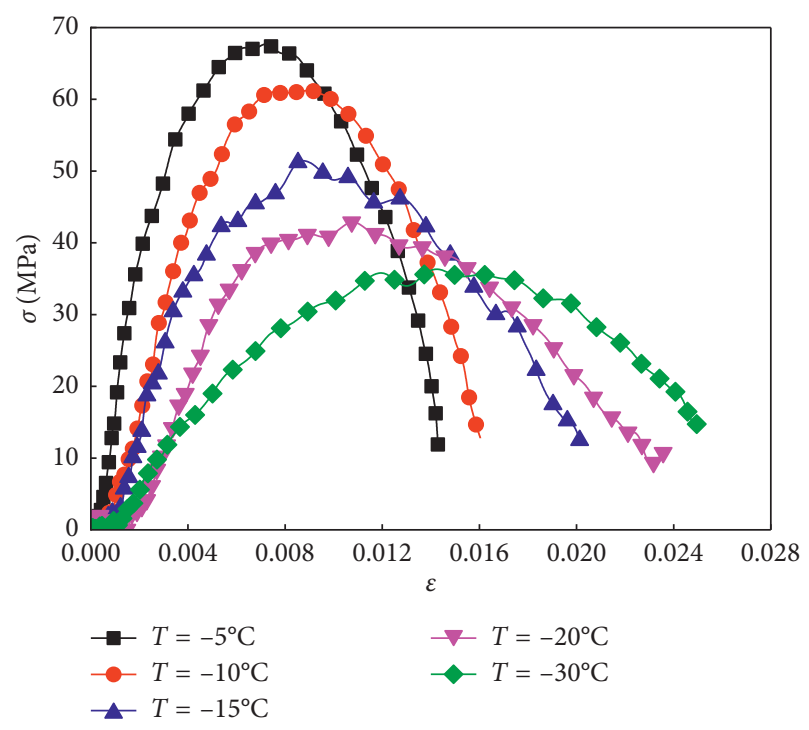

FIGURE 6: Stress-strain curves of yellow sandstone at different temperatures.

rule of sandstone scientifically, the fragmentation degree of sandstone fragments at different temperatures is screened by using a grading sieve. Since the smallest size of the pieces is $0 \mathrm{~mm}$, the largest size of the original pattern is $50 \mathrm{~mm}$, so this place is classified as $0-1 \mathrm{~mm}, 1-2.5 \mathrm{~mm}, 2.5-4 \mathrm{~mm}, 4-6 \mathrm{~mm}$, 6-8.5 mm, 8.5-11 Mm, 11-13 mm, 13-15 mm, and 15-50.0 $\mathrm{mm}$. After screening, electronic scales with high sensitivity are used to weigh each level of fragments and record the test data. Therefore, the fraction of the mass of fragments in the whole mass in the range of particle size $\eta_{\mathrm{li}}$ is calculated by the following equation [42]:

$$
\eta_{\mathrm{li}}=\frac{m_{\mathrm{li}}}{M}
$$

where $\eta_{\mathrm{li}}$ is the mass occupied by fragments with this particle size, $m_{\mathrm{li}}$ is the mass of fragments with this particle size, and $M$ is the total mass of samples.

Secondly, the percentage between the mass of fragments at all levels $m_{\mathrm{li}}$ and the initial total mass of samples $m_{\mathrm{d}}$ after screening is defined as the percentage of fragments $\eta_{\mathrm{li}}$; then, the average particle size of fragments in each grading group $d_{\mathrm{li}}$ is multiplied by the mass percentage of fragments under this particle size $\eta_{\text {li }}$ to obtain the size percentage of the group in all particle sizes $\delta$. At last, the percentage of particle size of fragments at all levels of the sample was accumulated to obtain the average particle size of the fragments. The relevant calculation expressions were as follows:

$$
\delta=\sum_{i=1}^{9} \delta_{\mathrm{li}}=\sum_{i=1}^{9} \eta_{\mathrm{li}} d_{\mathrm{li}}
$$

where $i$ is the number of grading sieve level, $i=1,2,3, \ldots, 9$, and $d_{1 \mathrm{i}}$ is the average particle size of the fragments in each level, which is calculated by taking the average mesh size of the two levels before and after the grading sieve.

Figure 7 shows the particle size distribution of yellow sandstone under different freeze-thaw temperatures. It can be seen that, with the decrease of freeze-thaw temperature, the proportion of fragments with large particle size (15$50 \mathrm{~mm}$ ) of yellow sandstone decreases, while that with small particle size increases. However, the overall average particle size shows a nearly linear downward trend.

\section{Influence of Freeze-Thaw Temperature on Energy Distribution of Yellow Sandstone}

4.1. Calculation Method of Dissipated Energy and Total Absorption Energy of Yellow Sandstone. Yellow sandstone is a typical physical change in the process of impact load, which is a process of transforming mechanical energy into internal energy [42-45]. However, the ultimate damage of yellow sandstone is a state instability phenomenon after internal energy accumulation reaches its limit driven by external energy [42]. Therefore, the energy carried by the stress wave can be calculated by the following equation $[42,44,45]$ :

$$
W=\frac{A C}{E} \int_{0}^{t} \sigma^{2}(t) \mathrm{d} t=A C E \int_{0}^{t} \varepsilon^{2}(t) \mathrm{d} t,
$$

where $A$ is the cross-sectional area of the incident bar and the transmission bar, which is $1963.49 \mathrm{~mm}^{2}$; $E$ is the elastic modulus of the input bar and the transmission bar, which is $210 \mathrm{GPa}$; and $C$ is the one-dimensional stress wave velocity. Since both the incident bar and the transmission bar are rigid bodies, $C$ is related to the density and elastic modulus $E$ of the incident bar. The relationship between them can be expressed in the following equation [42, 44, 45]:

$$
C=\sqrt{\frac{E}{\rho}}
$$

According to equations (3) and (4), the incident energy $W_{\mathrm{I}}$, reflected energy $W_{\mathrm{R}}$, and transmitted energy $W_{\mathrm{T}}$ in the dynamic impact process of SHPB can be expressed as $[42,44,45]$

$$
\left\{\begin{array}{l}
W_{\mathrm{I}}=A C E \int_{0}^{t} \varepsilon_{\mathrm{i}}^{2}(t) \mathrm{d} t, \\
W_{\mathrm{R}}=A C E \int_{0}^{t} \varepsilon_{\mathrm{r}}^{2}(t) \mathrm{d} t \\
W_{\mathrm{T}}=A C E \int_{0}^{t} \varepsilon_{\mathrm{t}}^{2}(t) \mathrm{d} t
\end{array}\right.
$$




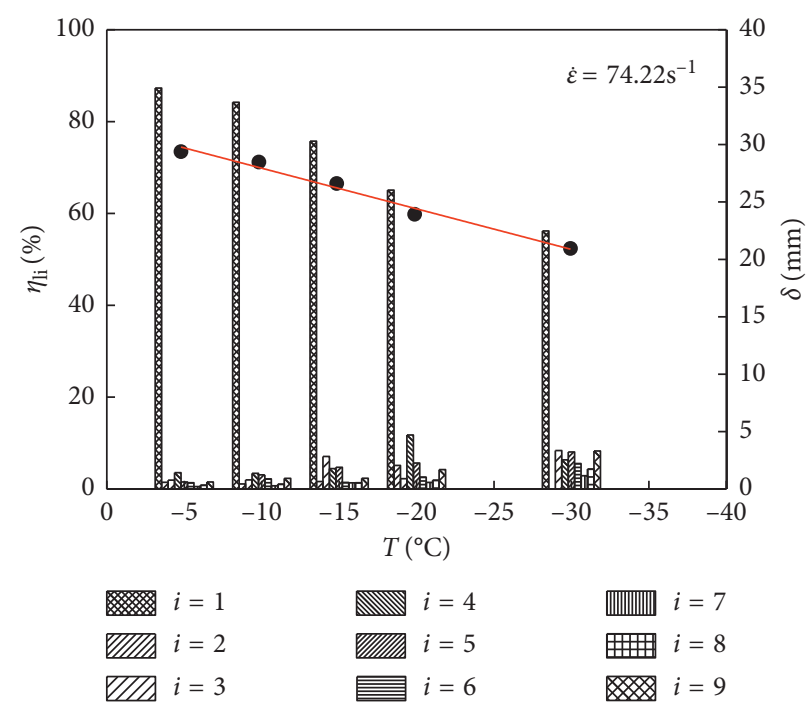

FIGURE 7: Distribution of yellow sandstone fragments at different freeze-thaw temperatures.

where $W_{\mathrm{I}}, W_{\mathrm{R}}$ and $W_{\mathrm{T}}$ are incident energy, reflected energy, and transmitted energy, respectively, $\varepsilon_{\mathrm{i}}(t)$ represents the strain under the action of the incident stress wave, $\varepsilon_{\mathrm{r}}(t)$ represents the strain under the action of the reflected stress wave, and $\varepsilon_{\mathrm{t}}(t)$ represents the strain under the action of the transmitted stress wave.

Based on the relationship between incident energy, reflected energy, and transmitted energy, the dissipated energy of sandstone under impact failure $W_{\mathrm{L}}$ can be finally obtained, as shown in the following equation $[42,44,45]$ :

$$
W_{\mathrm{L}}=W_{\mathrm{I}}-W_{\mathrm{R}}-W_{\mathrm{T}}
$$

In the process of studying the total absorption energy of yellow sandstone, the work done by external forces causes the deformation of yellow sandstone, so the area enclosed by the stress-strain curve and the $X$-axis is the total absorption energy $U[44,46]$, as shown in the following equation:

$$
U=\int \sigma \mathrm{d} \varepsilon
$$

\subsection{Influence of Freeze-Thaw Temperature on Each Energy} Variation of Sandstone. For brittle rocks, the effect of external impact is an input process of external energy to rocks [39]. When the rock is subjected to external mechanical energy, the absorption energy is converted to the internal energy of the rock, and when the energy accumulates more than the energy storage limits, the rock fractures, and the absorbed energy will transform into damage energy, plasticity energy, kinetic energy, heat and friction heat energy, radiant energy, and other forms of energy [43]. The research results show that the damage energy and kinetic energy account for $95 \%$ of all energies [45], so it is approximately believed that the total absorption energy of yellow sandstone under impact is converted into damage energy and kinetic energy $[45,46]$, and their relationship is shown in the following equation:

$$
U=W_{\mathrm{L}}+U_{\mathrm{e}}
$$

Figure 8 shows the relationship between energy and freeze-thaw temperature in yellow sandstone. It can be seen that, under the same strain rate and different freeze-thaw temperatures, the total absorption energy of yellow sandstone changes little, about $34 \mathrm{~J}$. With the increase of freezethaw temperature, the dissipation energy was $20.19 \mathrm{~J}$ at $-30^{\circ} \mathrm{C}$ and was $27.81 \mathrm{~J}$ at $-5^{\circ} \mathrm{C}$. And the former increases by $37.74 \%$. However, the kinetic energy first increases and then decreases with the increase of freeze-thaw temperature. It was the maximum of $12.49 \mathrm{~J}$ at $-15^{\circ} \mathrm{C}$ and was the minimum of $6.39 \mathrm{~J}$ at $-5^{\circ} \mathrm{C}$.

It can be seen from the changing relationship between the energy of the water-saturated yellow sandstone and the freeze-thaw temperature, water fills the cracks in the internal communication of the yellow sandstone. When the temperature drops rapidly, the water changes from liquid state to solid state, making the volume larger. Due to the time required for temperature transfer, the water on the outer surface of the yellow sandstone first condenses into solid ice when the temperature drops rapidly. And at this time, the internal cracks of the yellow sandstone are in a closed state. As the temperature continues to drop, the water from the outside to the inside changes from liquid to solid, which causes the volume of water to increase gradually. As the yellow sandstone is in a state of saturation, the water has filled all the connected pores and cracks in the interior of rocks, and the increase in the volume of water exerts an expansive force on the internal pores and cracks, causing the crack tips to be tensed apart from each other, or the bonding force of adjacent interfaces to be weaken [47]. When the temperature rises and the water is dissolved, the water flows from the original crack to the newly sprouted crack and redistributes in the yellow sandstone. And then the ice continues to exert an expansive force on the crack tip when refrozen. Therefore, when the temperature is lower, the temperature drops more rapidly within the same time, and 


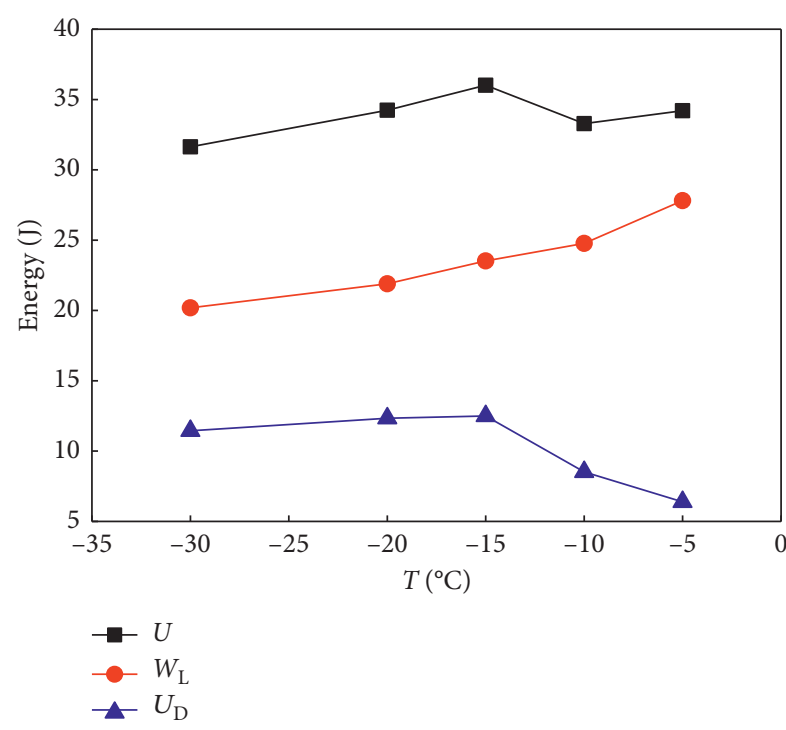

Figure 8: The relationship between each energy and freeze-thaw temperature in yellow sandstone.

the expansion force effect on crack growth and adhesion reduction is more obvious [48].

Due to the influence of freeze-thaw temperature, the ratio of total energy transforming into dissipated energy and kinetic energy depends on the physical and mechanical properties and the loading mode of yellow sandstone when it is subjected to impact load. At the same strain rate, as the temperature decreases, the cohesive force inside the yellow sandstone decreases, and the energy required to form the same crack area is less, thus the dissipated energy is smaller.

Meanwhile, in the process of dynamic impact compression, the transformation of internal energy of yellow sandstone leads to a dynamic process from deformation to damage sputtering of yellow sandstone $[39,43]$, which is characterized by the transformation and balance of total energy, dissipated energy, and kinetic energy. For a specific freeze-thaw temperature, there is a specific energy state corresponding to it.

\section{Influence of Freeze-Thaw Temperature on Sputtering Rate of Sandstone}

5.1. Influence of Freeze-Thaw Temperature on Sandstone Surface Energy. For sandstone, a brittle material, the dissipated energy is mainly in the form of surface energy that separates fragments from each other [43]. In order to further explore the influence of freeze-thaw temperature on yellow sandstone, fragments with different particle sizes are simplified into spheres of corresponding sizes, as shown in Figure 9 [42, 43].

The number of spheres within the diameter range of screening is calculated according to the following equation $[42,43]$ :

$$
n_{i}=\frac{m_{\mathrm{li}}}{4 \rho r_{i}^{3} \pi / 3}
$$

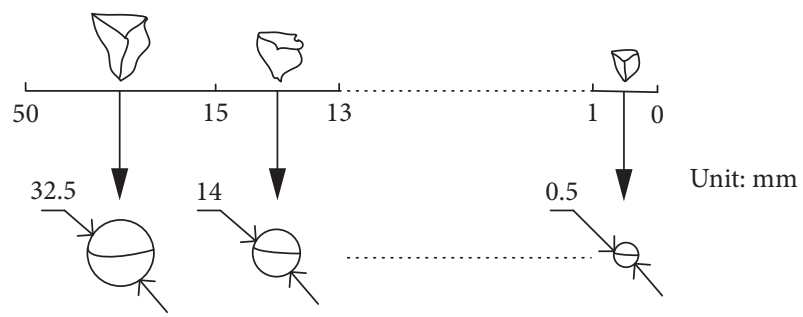

FIgURE 9: The schematic diagram of the fragments transformed into a sphere [40].

where $n_{i}$ is the quantity of sphere with dimension $i ; m_{i}$ is the mass of sphere with dimension $i ; \rho$ is the density of yellow sandstone, as $2395 \mathrm{Kg} / \mathrm{m}^{-3}$; and $r_{i}$ is the sphere radius transformed with dimension $i$.

Formula (9) can be used to obtain the number of spheres with different particle sizes, so that the surface area of fragments can be further calculated (10). By subtracting the upper and lower surface area and side area of the cylinder when it is not damaged from the surface area of all fragments, the internal damage area can be obtained, as shown in the following equation $[42,43]$ :

$$
S=\sum_{i=1}^{9} 4 n_{i} \pi r_{i}^{2}-2 \pi r h-2 \pi r^{2}
$$

where $r$ is the radius of sandstone sample in the impact test and $h$ is the height of sandstone sample in the impact test.

When the yellow sandstone is done work by external force, the energy accumulated inside will work on the yellow sandstone, leading to the fragmentation of each other, and the sum of energy required by the separation of all fragments is damage energy. As a brittle material, the dissipated energy of the yellow sandstone can be regarded as the surface energy when the yellow sandstone is broken, so the relationship between surface energy and dissipated energy is as follows [42-44]:

$$
W_{\mathrm{L}}=S \gamma
$$

Since most dissipated energy acts on the separation of all fragments, the relationship between dissipated energy and the surface area of fragments can be used to obtain the surface specific energy of sandstone fragments at per unit area $[42-44]$ :

$$
\gamma=\frac{W_{\mathrm{L}}}{S}
$$

Figure 10 shows the effect of freeze-thaw temperature on surface specific energy of sandstone. It can be seen from the figure that the broken surface area of yellow sandstone decreases gradually with the increase of freeze-thaw temperature. When the freeze-thaw temperature is $-30^{\circ} \mathrm{C}$, the broken surface area of yellow sandstone is $362.35 \mathrm{~cm}^{2}$. When the freeze-thaw temperature is $-5^{\circ} \mathrm{C}$, the broken surface area of yellow sandstone is $105.30 \mathrm{~cm}^{2}$, which decreases by $70.94 \%$ compared with that at $-30^{\circ} \mathrm{C}$. By fitting the surface area of yellow sandstone fragments with the freeze-thaw temperature, it is found that the surface area of yellow 


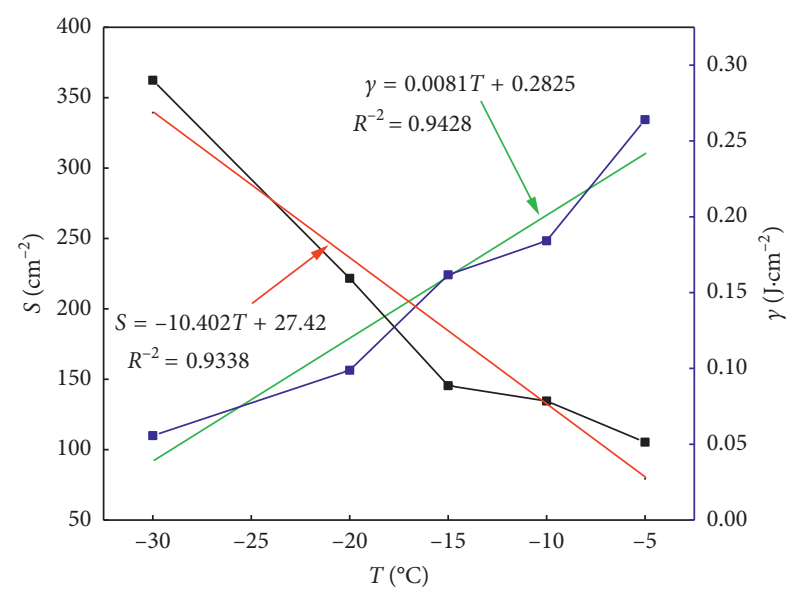

Figure 10: Effect of freeze-thaw cycle on surface energy of sandstone.

sandstone fragments decreases linearly with the increase of freeze-thaw temperature. However, the surface specific energy of yellow sandstone increases gradually with the increase of freeze-thaw temperature. When the freeze-thaw temperature is $-30^{\circ} \mathrm{C}$, the surface specific energy of yellow sandstone can be $0.056 \mathrm{~J} \cdot \mathrm{cm}^{-2}$. When the freeze-thaw temperature is increased to $-5^{\circ} \mathrm{C}$, the surface specific energy of yellow sandstone can be increased to $0.264 \mathrm{~J} \cdot \mathrm{cm}^{-2}$, which increases by $373.99 \%$ compared with that at $-30^{\circ} \mathrm{C}$. By fitting the surface specific energy of yellow sandstone with the freeze-thaw temperature, it is found that the surface specific energy of yellow sandstone decreases linearly with the increase of freeze-thaw temperature.

The lower the freezing-thawing temperature is, the faster the water condenses, which leads to the reduction of the cohesive force within the yellow sandstone. At the same strain rate, yellow sandstone with low freeze-thaw temperature requires a little energy to separate fragments from each other, which is consistent with the relationship between the freezethaw temperature and the average particle size of fragments.

5.2. Influence of Freeze-Thaw Cycle on Sputtering Rate of Yellow Sandstone. When the water-saturated yellow sandstone after freeze-thaw cycle is subjected to impact load, a part of the whole absorbed energy converts into dissipated energy to separate fragments from each other and the other part converts into kinetic energy of fragments. In order to study the influence of freeze-thaw temperature on the sputtering rate of fragments of yellow sandstone, assume that the kinetic energy ratio is $K$, so the total absorbed energy of yellow sandstone in the impact process is distributed as follows [43]:

$$
\left\{\begin{array}{l}
\sum_{i=1}^{9} \frac{2}{3} \rho \pi r_{i}^{3} v^{2}=k U, \\
\left(\sum_{i=1}^{9} 4 \pi n_{i} r_{i}^{2}-2 \pi R H-2 \pi R^{3}\right) \gamma=(1-K) U,
\end{array}\right.
$$

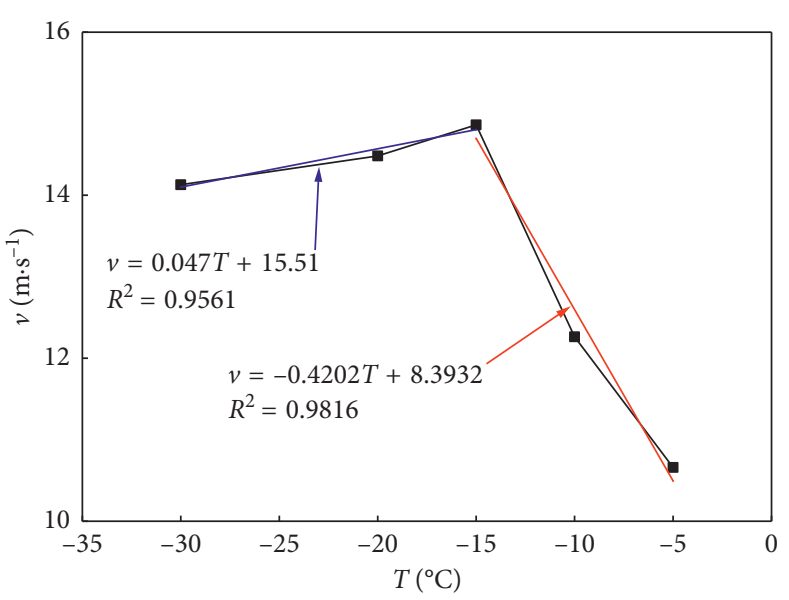

FIgURE 11: Relationship between the sputtering rate and temperature.

where $v$ is the sputtering rate of the fragments and $K$ is the proportion of kinetic energy in the total energy of yellow sandstone.

According to equation (13), the sputtering rate of yellow sandstone fragments after crushing under the impact load is $v$, and the final expression is shown in the following equation [43]:

$$
\left(v=\sqrt{\frac{k}{1-k} \frac{\left[4 \pi\left(3 R^{2} H / 4\right)^{2 / 3}\left(\sum_{i=1}^{9} n_{i}\right)^{1 / 3}-2 \pi R H-2 \pi R^{2}\right] \gamma}{1 / 2 \rho \pi R^{2} H}}\right)
$$

According to equations [13] and [14] and the energy value of yellow sandstone calculated previously, the sputtering rate of yellow sandstone fragments under the impact load can be obtained. By combining the sputtering rate and freeze-thaw temperature, the variation rule between them can be obtained.

Figure 11 shows the relationship between the sputtering rate of yellow sandstone fragments and temperature. It can be seen from the figure that there are significant differences between the deceleration rate of yellow sandstone fragments and the freeze-thaw temperature. The main performance is that, when the freezethaw temperature ranges from $-30^{\circ} \mathrm{C}$ to $-15^{\circ} \mathrm{C}$, the sputtering rate of yellow sandstone fragments gradually increases with the increase of freeze-thaw temperature. When the temperature is $-30^{\circ} \mathrm{C}$, the sputtering speed of yellow sandstone fragments is $14.13 \mathrm{~m} \cdot \mathrm{s}^{-1}$. When the temperature is $-15^{\circ} \mathrm{C}$, the sputtering speed of yellow sandstone fragments is $14.86 \mathrm{~m} \cdot \mathrm{s}^{-1}$, which increases by $5.20 \%$ compared with that at $-30^{\circ} \mathrm{C}$. However, when the freeze-thaw temperature ranges from $-15^{\circ} \mathrm{C}$ to $-5^{\circ} \mathrm{C}$, the sputtering rate of yellow sandstone fragments gradually increases with the increase of freeze-thaw temperature. When the temperature is $-5^{\circ} \mathrm{C}$, the sputtering rate of yellow sandstone fragments is $14.13 \mathrm{~m} \cdot \mathrm{s}^{-1}$, which increased by $28.27 \%$ compared with that at $-15^{\circ} \mathrm{C}$. 

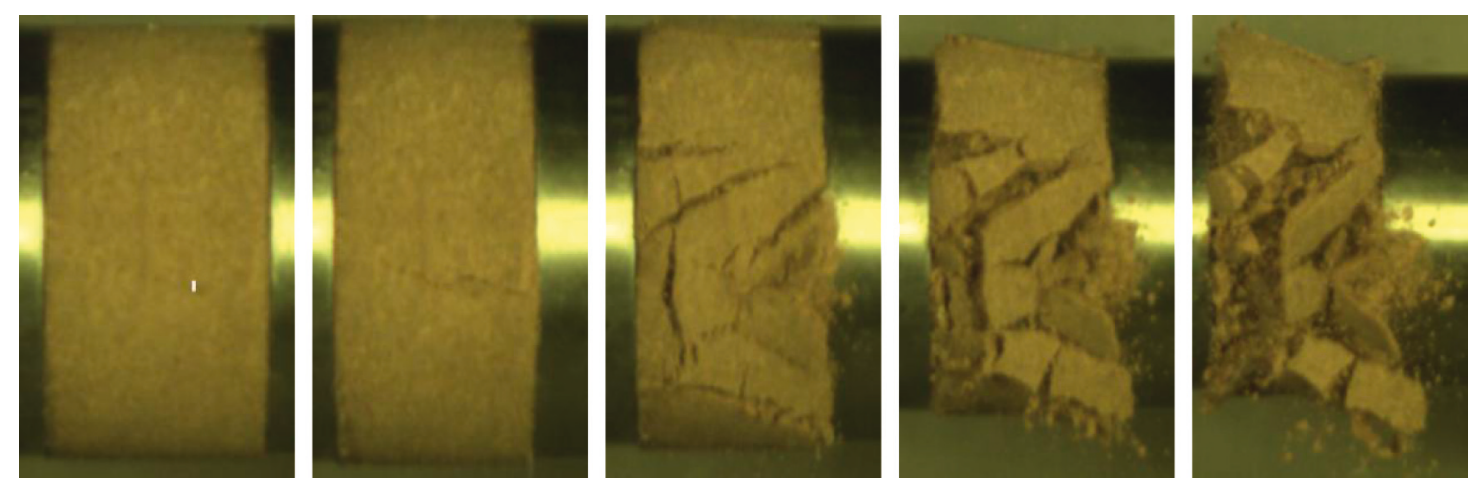

(a)
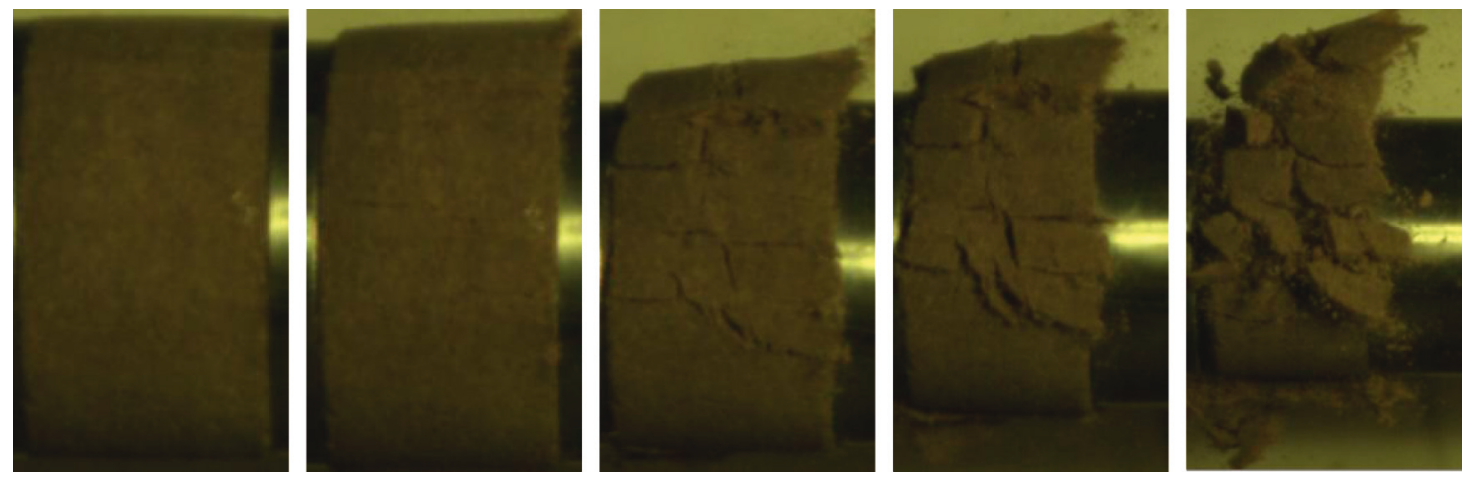

(b)
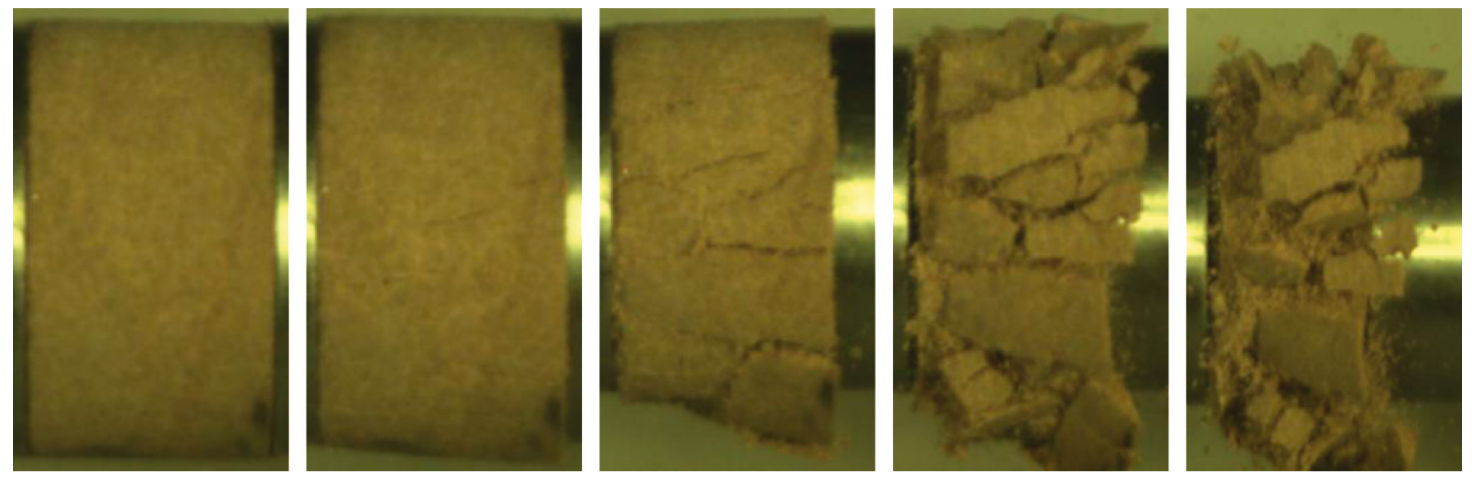

(c)
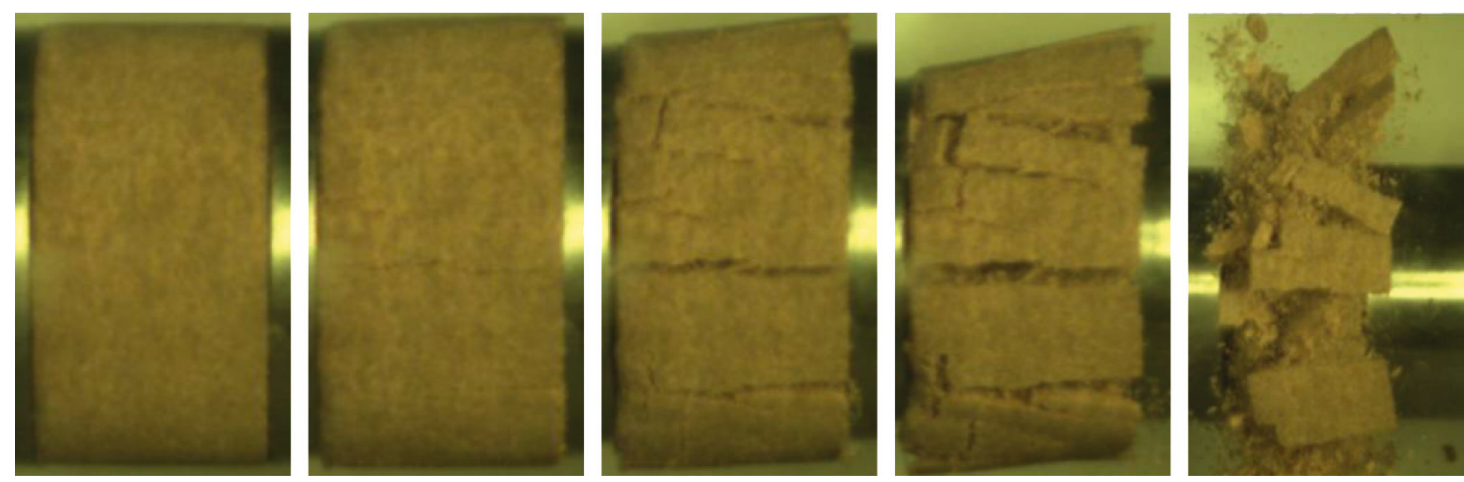

(d)

Figure 12: Continued. 

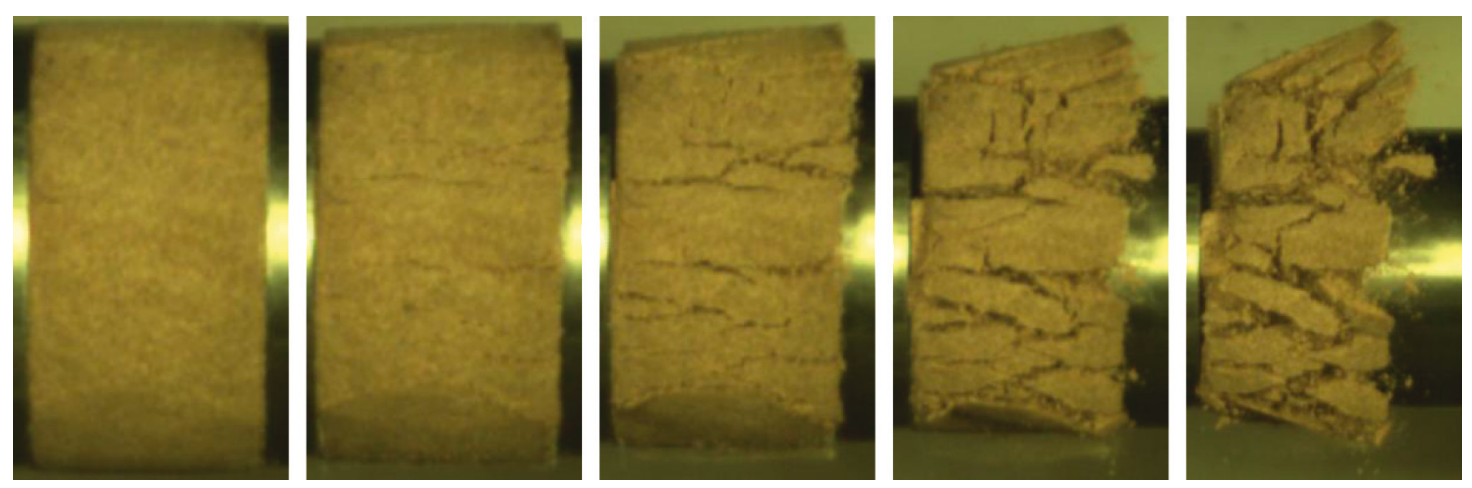

(e)

Figure 12: The macroscopic damage process of yellow sandstone under different freeze-thaw temperatures: (a) $T=-5^{\circ} \mathrm{C},(\mathrm{b}) \mathrm{T}=-10^{\circ} \mathrm{C}$, (c) $\mathrm{T}=-15^{\circ} \mathrm{C}$, (d) $\mathrm{T}=-20^{\circ} \mathrm{C}$, and (e) $\mathrm{T}=-30^{\circ} \mathrm{C}$.

5.3. High-Speed Photography of Dynamic Failure Process of Yellow Sandstone under Different Freeze-Thaw Temperatures. In order to observe the impact of freeze-thaw temperature on the whole fracture process of yellow sandstone more intuitively, high-speed camera is adopted to film the whole process of impact load on yellow sandstone with different freeze-thaw temperatures. The dynamic fracture process of yellow sandstone can be recorded by high-speed camera. So the initiation of cracks, cracking development, fragment separation, and fragmentation sputtering process of yellow sandstone can be observed from the deformation and failure of yellow sandstone in the whole process. And five typical state pictures are selected, which are, respectively, the first contact of the incident bar with the sample, the first visible crack of the sample surface, the complete distribution of the sample cracks, the separation of the sample fragments, and the sputtering of the separated fragments to the surrounding areas.

Figure 12 shows the macroscopic damage process of yellow sandstone under different freeze-thaw temperatures. From the dynamic failure process of yellow sandstone, we can get the following information: It can be seen that the deformation and failure process of yellow sandstone under impact at different freeze-thaw temperatures are roughly the same, which all go through stages of compaction, crack generation, crack growth, fragment separation, and fragmentation sputtering. But the stages are different. When the freeze-thaw temperature is lower, the crack density of yellow sandstone is higher and the final fracture is more severe, which is consistent with the previous particle size distribution. The effect of freezing and thawing temperature on the sputtering rate of the saturated yellow sandstone is mainly reflected in the fact that the fragments are separated from each other and sputtered in the direction of rod motion. The higher the sputtering rate, the greater the distance from the center of mass of the fragments and the smaller the distance from the system axis. According to the final sputtering results, the freezing and thawing temperatures of $-15^{\circ} \mathrm{C},-10^{\circ} \mathrm{C}$, and $-5^{\circ} \mathrm{C}$ are more severe than those of $-20^{\circ} \mathrm{C}$ and $-30^{\circ} \mathrm{C}$, and the freezing and thawing temperature is $-15^{\circ} \mathrm{C}$. The fragmentation at ${ }^{\circ} \mathrm{C}$ is the most severe, which is consistent with the sputtering rate of the yellow sandstone fragments at different temperatures.

\section{Conclusions}

In this paper, firstly, Hopkinson pressure bar is used to conduct dynamic impact on the water-saturated yellow sandstone treated with five different freeze-thaw temperatures under the same strain rate. Secondly, the yellow sandstone fragments after impact are screened by a grading sieve, and the mass of fragments with different particle sizes after screening is counted. Then, fragments with different particle sizes are transformed into spheres with corresponding particle sizes. So the surface specific energy of yellow sandstone at different freeze-thaw temperatures can be obtained by combining dissipative energy. Finally, the sputtering rate of the fragments is obtained by using the relationship of total energy, dissipated energy, and kinetic energy. The main conclusions are as follows:

(1) The elastic modulus and peak stress decrease with the decrease of freeze-thaw temperature, while the peak strain and unloading elastic modulus decrease with the freeze-thaw temperature, indicating the mechanical properties of freeze-thaw temperature on saturated yellow sandstone. The impact is significant, and the freeze-thaw temperature changes to some extent change the internal structure of the yellow sandstone, reducing its crucible bearing capacity and resistance to deformation. The freeze-thaw temperature has a significant effect on the damage of the yellow sandstone. The lower the freezing temperature, the more obvious the damage of the yellow sandstone. The smaller the particle size distribution of the fragments, the lower the freeze-thaw temperature, the weaker the interface adhesion of the yellow sandstone, the same strain. At the rate, the lower the freeze-thaw temperature is, the more severe the yellow sandstone is destroyed, and the internal damage is more serious.

(2) The dissipated energy of yellow sandstone increases with the decrease of freezing temperature. The relationship 
between dissipative energy and freeze-thaw temperature indicates that more cracks are formed inside the yellow sandstone. The generation of these cracks consumes more energy. The kinetic energy gradually increases at a freeze-thaw temperature of $-30^{\circ} \mathrm{C}$ to $-15^{\circ} \mathrm{C}$ and gradually decreases at $-15^{\circ} \mathrm{C}$ to $-5^{\circ} \mathrm{C}$. The variation of kinetic energy with freeze-thaw temperature shows that the distribution of internal energy of the yellow sandstone is different for the same loading rate.

(3) The surface area of the yellow sandstone fragments increases with the increase of the freezing and thawing temperature, the surface specific energy decreases with the decrease of the freezing temperature, and the surface specific energy decreases with the temperature, indicating that the saturated yellow sandstone is different. At freezing and thawing temperature, the bond strength per unit area is gradually weakened. Under the impact load with the same strain rate, the yellow sandstone with weaker interface force is more likely to break up to form more fragments, thus showing freezing and thawing. The lower the temperature, the larger the surface area of the fragments.

(4) The freezing and thawing temperature is $-5^{\circ} \mathrm{C}$, $-10^{\circ} \mathrm{C},-15^{\circ} \mathrm{C},-20^{\circ} \mathrm{C},-30^{\circ} \mathrm{C}$. The sputtering conditions of $-15^{\circ} \mathrm{C},-10^{\circ} \mathrm{C}$, and $-5^{\circ} \mathrm{C}$ compared with $-20^{\circ} \mathrm{C}$ and $-30^{\circ} \mathrm{C}$ are more severe, and the freezing and melting temperature of $-15^{\circ} \mathrm{C}$ is the most severe, indicating that the freezing and thawing temperature is lowered. The sputtering conditions of $-15^{\circ} \mathrm{C},-10^{\circ} \mathrm{C}$ and $-5^{\circ} \mathrm{C}$ compared with $-20^{\circ} \mathrm{C}$ and $-30^{\circ} \mathrm{C}$ are more severe, and the freezing and melting temperature of $-15^{\circ} \mathrm{C}$ is the most severe, indicating that the freezing and thawing temperature is lowered. The surface specific energy of the saturated yellow sandstone changes its energy distribution ratio. Therefore, under the impact load with the same strain rate, the freezing rate of the freeze-thaw temperature is $-15^{\circ} \mathrm{C}$.

\section{Data Availability}

The data used to support the findings of this study are available from the corresponding author upon request.

\section{Conflicts of Interest}

The authors declare that they have no conflicts of interest.

\section{Acknowledgments}

The authors gratefully acknowledge the financial support of this study provided by the "National Science and Technology Major Project (2016ZX05045002-003).”

\section{References}

[1] M. A. Coombes, H. A. Viles, and H. Zhang, "Thermal blanketing by ivy (Hedera helix L.) can protect building stone from damaging frosts," Scientific Reports, vol. 8, no. 1, p. 9834, 2018.

[2] T. C. Hales and J. J. Roering, "Climatic controls on frost cracking and implications for the evolution of bedrock landscapes," Journal of Geophysical Research: Earth Surface, vol. 112, no. F2, 2007.

[3] N. A. Beier and D. C. Sego, "Cyclic freeze-thaw to enhance the stability of coal tailings," Cold Regions Science and Technology, vol. 55, no. 3, pp. 278-285, 2009.

[4] H. P. Xie, Y. Ju, and L. Y. Li, "Criteria for strength and structural failure of rocks based on energy dissipation and energy release principles," Chinese Journal of Rock Mechanics and Engineering, vol. 24, no. 17, pp. 3003-3010, 2005.

[5] H. P. Xie, Y. Ju, L. Y. Li et al., "Energy mechanism of deformation and failure of rock masses," Chinese Journal of Rock Mechanics and Engineering, vol. 27, no. 9, pp. 1729-1739, 2008.

[6] N. West, E. Kirby, A. A. Nyblade, and S. L. Brantley, "Climate preconditions the Critical Zone: elucidating the role of subsurface fractures in the evolution of asymmetric topography," Earth and Planetary Science Letters, vol. 513, pp. 197-205, 2019.

[7] M.-C. Eppes and R. Keanini, "Mechanical weathering and rock erosion by climate-dependent subcritical cracking," Reviews of Geophysics, vol. 55, no. 2, pp. 470-508, 2017.

[8] P. Viklander, "Laboratory study of stone heave in till exposed to freezing and thawing," Cold Regions Science and Technology, vol. 27, no. 2, pp. 141-152, 1998.

[9] R. S. Anderson, S. P. Anderson, and G. E. Tucker, "Rock damage and regolith transport by frost: an example of climate modulation of the geomorphology of the critical zone," Earth Surface Processes and Landforms, vol. 38, no. 3, pp. 299-316, 2013.

[10] J. Kruschwitz and J. Bluhm, "Modeling of ice formation in porous solids with regard to the description of frost damage," Computational Materials Science, vol. 32, no. 3-4, pp. 407-417, 2005.

[11] J. R. Blachere and J. E. Young, "Failure of capillary theory of frost damage as applied to ceramics," Journal of the American Ceramic Society, vol. 57, no. 5, pp. 212-216, 1974.

[12] M. Fener and İ. İnce, "Effects of the freeze-thaw (F-T) cycle on the andesitic rocks (Sille-Konya/Turkey) used in construction building," Journal of African Earth Sciences, vol. 109, pp. 96-106, 2015.

[13] D. H. Everett, "The thermodynamics of frost damage to porous solids," Transactions of the Faraday Society, vol. 57, pp. 1541-1551, 1961.

[14] J. Park, C.-U. Hyun, and H.-D. Park, "Changes in microstructure and physical properties of rocks caused by artificial freeze-thaw action," Bulletin of Engineering Geology and the Environment, vol. 74, no. 2, pp. 555-565, 2015.

[15] Y. Inada and K. Yokota, "Some studies of low temperature rock strength," International Journal of Rock Mechanics and Mining Sciences \& Geomechanics Abstracts, vol. 21, no. 3, pp. 145-153, 1984.

[16] F. Bayram, "Predicting mechanical strength loss of natural stones after freeze-thaw in cold regions," Cold Regions Science and Technology, vol. 83-84, pp. 98-102, 2012.

[17] H. Deng, S. Yu, J. Deng et al., "Experimental investigation on energy mechanism of freezing-thawing treated sandstone under uniaxial static compression," KSCE Journal of Civil Engineering, vol. 23, no. 3, pp. 1-9, 2019.

[18] V. Penttala and F. Al-Neshawy, "Stress and strain state of concrete during freezing and thawing cycles," Cement and Concrete Research, vol. 32, no. 9, pp. 1407-1420, 2002. 
[19] M. Koniorczyk, D. Gawin, and B. A. Schrefler, "Modeling evolution of frost damage in fully saturated porous materials exposed to variable hygro-thermal conditions," Computer Methods in Applied Mechanics and Engineering, vol. 297, pp. 38-61, 2015.

[20] D. Codeglia, N. Dixon, G. J. Fowmes, and G. Marcato, "Analysis of acoustic emission patterns for monitoring of rock slope deformation mechanisms," Engineering Geology, vol. 219, pp. 21-31, 2017.

[21] J. B. Murton, O. Kuras, M. Krautblatter et al., "Monitoring rock freezing and thawing by novel geoelectrical and acoustic techniques," Journal of Geophysical Research: Earth Surface, vol. 121, no. 12, pp. 2309-2332, 2016.

[22] L. Girard, S. Gruber, S. Weber, and J. Beutel, "Environmental controls of frost cracking revealed through in situ acoustic emission measurements in steep bedrock," Geophysical Research Letters, vol. 40, no. 9, pp. 1748-1753, 2013.

[23] V. G. R. De Argandoña, A. R. Rey, C. Celorio, L. M. S. del Río, L. Calleja, and J. Llavona, "Characterization by computed $\mathrm{X}$-ray tomography of the evolution of the pore structure of a dolomite rock during freeze-thaw cyclic tests," Physics and Chemistry of the Earth, Part A: Solid Earth and Geodesy, vol. 24, no. 7, pp. 633-637, 1999.

[24] C. H. Sondergeld and C. S. Rai, "Velocity and resistivity changes during freeze-thaw cycles in Berea sandstone," Geophysics, vol. 72, no. 2, pp. E99-E105, 2007.

[25] P. A. Duvillard, A. Revil, Y. Qi, A. Soueid Ahmed, A. Coperey, and L. Ravanel, "Three-dimensional electrical conductivity and induced polarization tomography of a rock glacier," Journal of Geophysical Research: Solid Earth, vol. 123, no. 11, pp. 9528-9554, 2018.

[26] I. Ince and M. Fener, "A prediction model for uniaxial compressive strength of deteriorated pyroclastic rocks due to freeze-thaw cycle," Journal of African Earth Sciences, vol. 120, pp. 134-140, 2016.

[27] Z. Zhou, K. Xing, H. Yang, and H. Wang, "Damage mechanism of soil-rock mixture after freeze-thaw cycles," Journal of Central South University, vol. 26, no. 1, pp. 13-24, 2019.

[28] C. M. Steelman, C. S. Kennedy, D. C. Capes, and B. L. Parker, "Electrical resistivity dynamics beneath a fractured sedimentary bedrock riverbed in response to temperature and groundwater-surface water exchange," Hydrology and Earth System Sciences, vol. 21, no. 6, pp. 3105-3123, 2017.

[29] T. Yamabe and K. M. Neaupane, "Determination of some thermo-mechanical properties of Sirahama sandstone under subzero temperature condition," International Journal of Rock Mechanics and Mining Sciences, vol. 38, no. 7, pp. 1029-1034, 2001.

[30] Q. Li, L. Chen, Z. Sui et al., "Dynamic analysis and criterion evaluation on rockburst considering the fractured dissipative energy," Advances in Mechanical Engineering, vol. 11, no. 3, article 1687814019825906, 2019.

[31] J. Kodama, T. Goto, Y. Fujii, and P. Hagan, "The effects of water content, temperature and loading rate on strength and failure process of frozen rocks," International Journal of Rock Mechanics and Mining Sciences, vol. 62, pp. 1-13, 2013.

[32] S. Demirdag, "Effects of freezing-thawing and thermal shock cycles on physical and mechanical properties of filled and unfilled travertines," Construction and Building Materials, vol. 47, pp. 1395-1401, 2013.

[33] K.-P. Zhou, B. Li, J.-L. Li, H.-W. Deng, and F. Bin, "Microscopic damage and dynamic mechanical properties of rock under freeze-thaw environment," Transactions of Nonferrous Metals Society of China, vol. 25, no. 4, pp. 1254-1261, 2015.
[34] P. Wang, J. Xu, S. Liu, S. Liu, and H. Wang, "A prediction model for the dynamic mechanical degradation of sedimentary rock after a long-term freeze-thaw weathering: considering the strain-rate effect," Cold Regions Science and Technology, vol. 131, pp. 16-23, 2016.

[35] P. Wang, J. Xu, S. Liu, H. Wang, and S. Liu, "Static and dynamic mechanical properties of sedimentary rock after freeze-thaw or thermal shock weathering," Engineering $\mathrm{Ge}$ ology, vol. 210, pp. 148-157, 2016.

[36] P. Wang, J. Xu, X. Fang, and P. Wang, "Energy dissipation and damage evolution analyses for the dynamic compression failure process of red-sandstone after freeze-thaw cycles," Engineering Geology, vol. 221, pp. 104-113, 2017.

[37] B. Ke, K. Zhou, H. Deng et al., "NMR pore structure and dynamic characteristics of sandstone caused by ambient freeze-thaw action," Shock and Vibration, vol. 2017, Article ID 9728630, 10 pages, 2017.

[38] B. Ke, K. Zhou, C. Xu, H. Deng, J. Li, and F. Bin, "Dynamic mechanical property deterioration model of sandstone caused by freeze-thaw weathering," Rock Mechanics and Rock Engineering, vol. 51, no. 9, pp. 2791-2804, 2018.

[39] L. Y. Li, Y. Ju, Z. W. Zhao et al., "Energy analysis of rock structure under static and dynamic loading conditions," Journal of China Coal Society, vol. 34, no. 6, pp. 737-741, 2009.

[40] C. Liu, H. Deng, H. Zhao, and J. Zhang, "Effects of freeze-thaw treatment on the dynamic tensile strength of granite using the Brazilian test," Cold Regions Science and Technology, vol. 155, pp. 327-332, 2018.

[41] D. Ma, Q. Ma, and P. Yuan, "SHPB tests and dynamic constitutive model of artificial frozen sandy clay under confining pressure and temperature state," Cold Regions Science and Technology, vol. 136, pp. 37-43, 2017.

[42] A. Lu, S. Hu, M. Li et al., "Impact of moisture content on the dynamic failure energy dissipation characteristics of sandstone," Shock and Vibration, vol. 2019, Article ID 6078342, 10 pages, 2019.

[43] Z. Zhang and F. Gao, Energy Evolution Mechanism during Rock Deformation and Failure, China University of Mining and Technology, Beijing, China, 2013.

[44] L. Y. Li, Z. J. Xu, H. P. Xie et al., "Failure experimental study on energy laws of rock under differential dynamic impact velocities," Journal of China Coal Society, vol. 36, no. 12, pp. 2007-2011, 2011.

[45] L. Ming, Research on Rupture Mechanisms of Coal Measures Sandstone under High Temperature and Impact Load, China University of Mining and Technology, Xuzhou, China, 2014.

[46] S. Hu, Study on Mechanical Properties and Energy Response Characteristics of High-Porosity Concrete under Cyclic Loading and Unloading, China University of Mining and Technology, Xuzhou, China, 2018.

[47] O. Coussy and P. Monteiro, "Unsaturated poroelasticity for crystallization in pores," Computers and Geotechnics, vol. 34, no. 4, pp. 279-290, 2007.

[48] M. J. Setzer, "Micro-ice-lens formation in porous solid," Journal of Colloid and Interface Science, vol. 243, no. 1, pp. 193-201, 2001. 


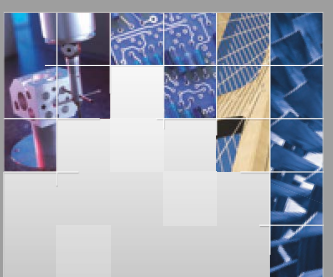

\section{Enfincering}
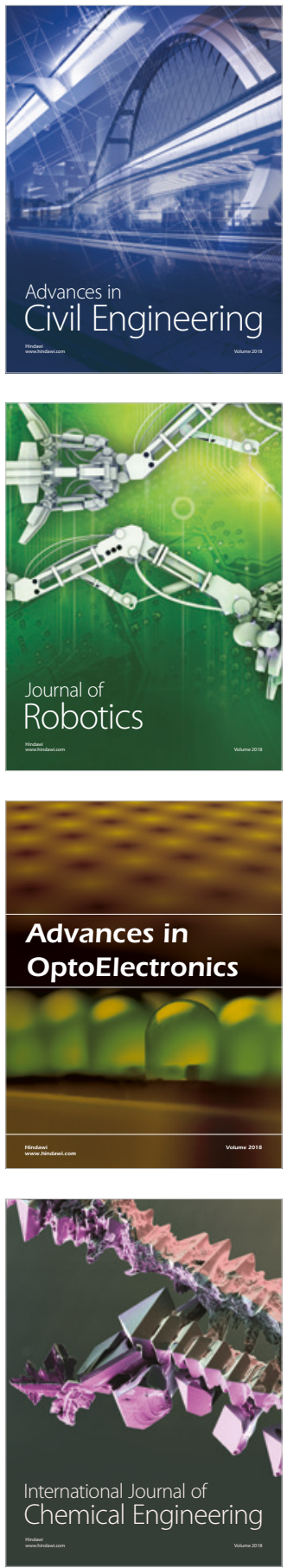

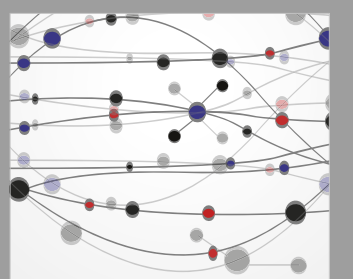

\section{Rotating \\ Machinery}

The Scientific World Journal

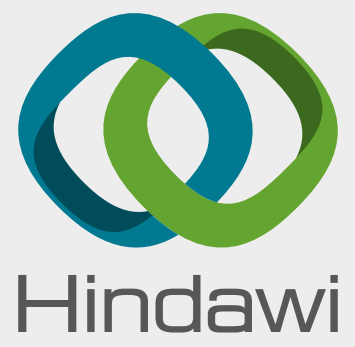

Submit your manuscripts at

www.hindawi.com
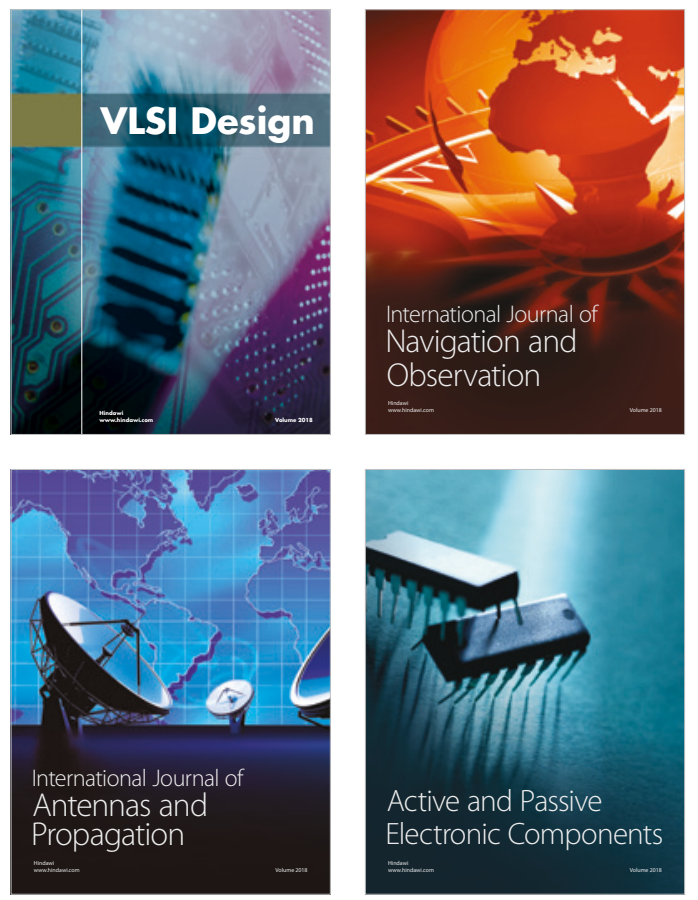
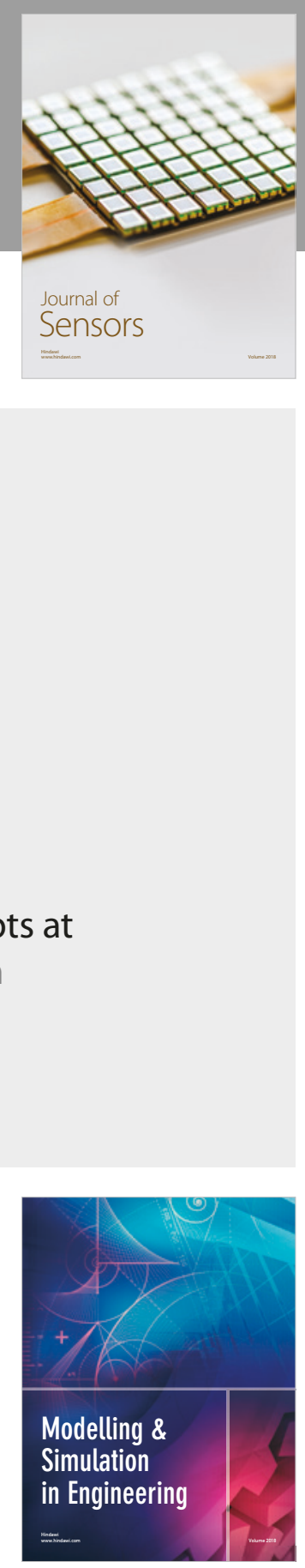

\section{Advances \\ Multimedia}
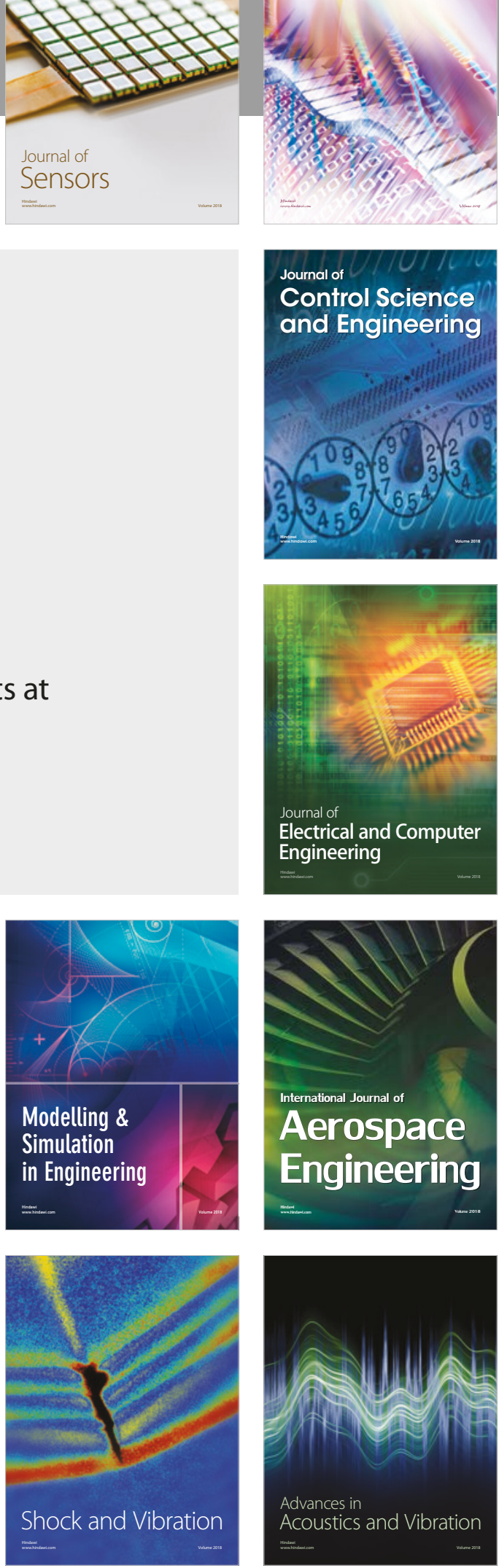